\title{
ANÁLISE DE ESTRATÉGIA DE MUDANÇA DA MARCA ACRESCENTANDO VALOR: UM ESTUDO DA VALE
}

\author{
Analysis the brand change strategy of adding value: \\ a study of the company Vale
}

Recebido em 05.10.09 / Aceito em 15.01.10

\section{Ana Luiza Gontijo Chiabi ${ }^{1}$ e Carlos Alberto Gonçalves ${ }^{2}$}

\section{Resumo}

Os estudos de mudanças de marca mostram ser oportuno verificar a sua comunicação, impactos no valor. Essas ações são estratégicas para as firmas, tendo em vista que as marcas são consideradas um ativo de valor e influenciam na reputação, desempenho de mercado e expansão da empresa. Para alcançar o status de alto valor da marca a tendência é que as empresas criem uma identidade com o objetivo de acrescentar um conceito de valor positivo, a fim de desenvolver marcas com estima e qualidade visual, funcionalidade e conexão com os seus públicos.

Palavras-chave: Brand equity; Posicionamento da marca; Nova marca; Valor da marca.

\section{Abstract}

The study of brand change is appropriate to examine its communication, the impact of Brand Equity. These decisions are strategic to firms considering that the brands are considered a value business asset and its reputation influence, market performance and company expansion. To achieve the status of high Brand Equity is a trend that companies create an identity in sense to add the concept of positive value in order to develop brands desired and visual quality, functionality and connection with their audiences.

Keywords: Brand equity; Brand positioning; New brand; Brand change.

\footnotetext{
${ }^{1}$ Profissional Gestão da Mudança Organizacional e Especialista em Marketing UFMG. E-mail: anachiabi@yahoo.com.br 2 Professor - FUMEC e UFMG. E-mail: Carlos@face.ufmg.br
} 


\section{Introdução}

O mercado global exige diversificação dos produtos e negócios, estratégias e novas tecnologias para sobrevivência das organizações. A competição intensa contribui para o novo posicionamento da marca, tornando-se elemento crítico para o sucesso de liderança de uma empresa no mercado. Ao buscar por um posicionamento estável e dominante no mercado, destaca a importância do valor da marca associado à escolha do consumidor. Estudos realizados especialmente na literatura de Marketing mostram a tendência de novas dinâmicas e disciplinas para concretizar a relação marca versus consumo.

Para a empresa mineradora Vale, antiga Vale do Rio Doce, a estratégia de posicionamento da nova marca tem como principais objetivos criar cultura de marca para o público interno, remover a antiga marca dos ativos no mundo, alinhar o discurso interno à nova marca para relacionamento com os stakeholders, fortalecer o valor da marca nos diferentes níveis da organização para suportar a gestão da nova identidade visual.

A Vale anunciou, em novembro de 2007, a reformulação visual em seu logotipo e mudanças em sua marca. A estratégia da mudança teve seu foco no nome como o grupo é conhecido no mercado: Vale. As iniciais CVRD, que representavam a logomarca da empresa, foram substituídas pela nova marca em todos os produtos, materiais e qualquer forma de comunicação visual e divulgação da empresa (Figura 1).

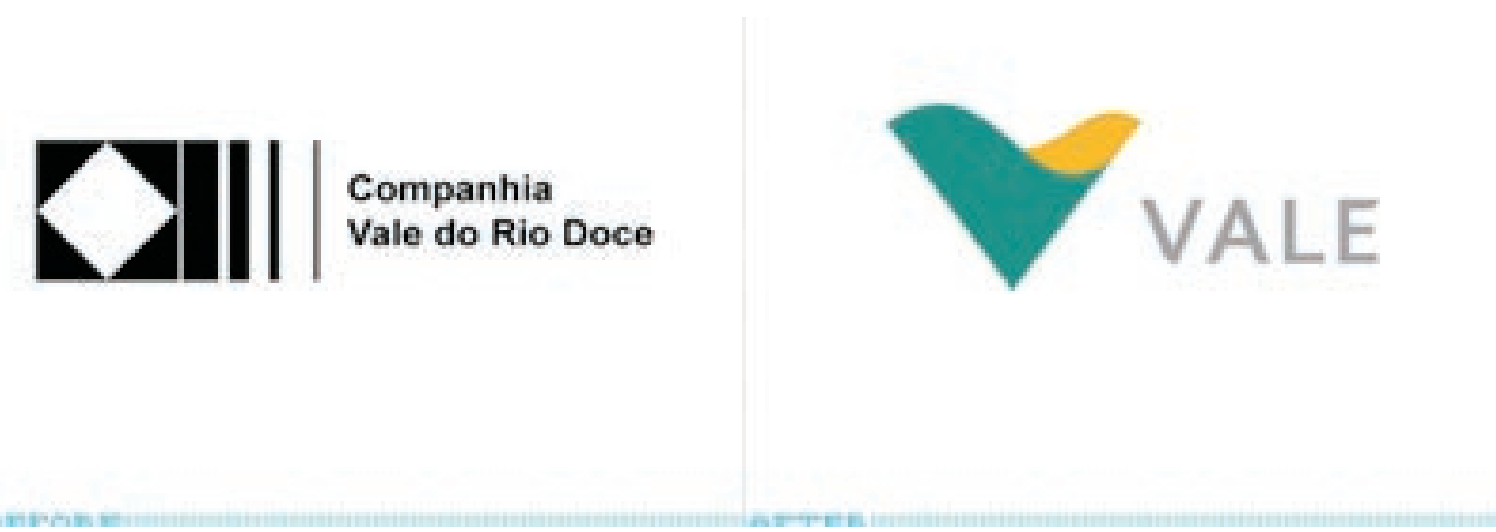

Figura 1 - Antiga e nova marca

\section{Conceito de brand equity}

A teorização do conceito de brand equity é um fenômeno recente, sua primeira exibição foi desenvolvida no artigo de Gardner e Levy, publicado na Harvard Business Review, em 1955, encontrando-se fortemente associada à noção de "imagem de marca", que é o conjunto de atributos de associações que os consumidores conectam ao nome de marca. (BIEL, 1993, p.71). Essa teoria foi, até os anos 1980, bem periférica em relação ao marketing, e considerada insuficiente para ser incorporada nas práticas profissionais (FELDWICK, 1996, p. 93).

Por se tratar de uma teoria pouco estudada na década de 1980, o brand equity teve sua percepção retardada pelos efeitos do mercado e sinais de necessidade do valor da marca na época. Com o desenvolvimento do âmbito econômico das grandes empresas ligadas à bolsa de 
valores, fusões e aquisições, a estratégia de valorização da marca foi, aos poucos, sendo notada e aperfeiçoada de acordo com a progressiva conscientização da importância da imagem da marca no circuito monetário. Como reflexo dessa percepção, a prática do marketing foi ganhando espaço no paradigma da globalização.

Nesse contexto, o conceito de brand equity assume relevância ao integrar e concretizar o novo paradigma. A pluralidade de perspectivas e definições de brand equity, patente na literatura, condiciona e limita o desenvolvimento de um construto integrador e consensual (LOURO, 2000). Essa diversidade pode ser ilustrada pela identificação de algumas das concepções mais difundidas do brand equity, nas quais Aaker foi pioneiro (Figura 2). Segundo Aaker (1998), os ativos nos quais se baseam o brand equity podem ser agrupados em cinco categorias: lealdade à marca, conhecimento do nome, qualidade percebida, associações à marca em acréscimo à qualidade percebida, outros ativos do proprietário da marca (palestrantes, trademarks, relações com canais de distribuição, entre outros).

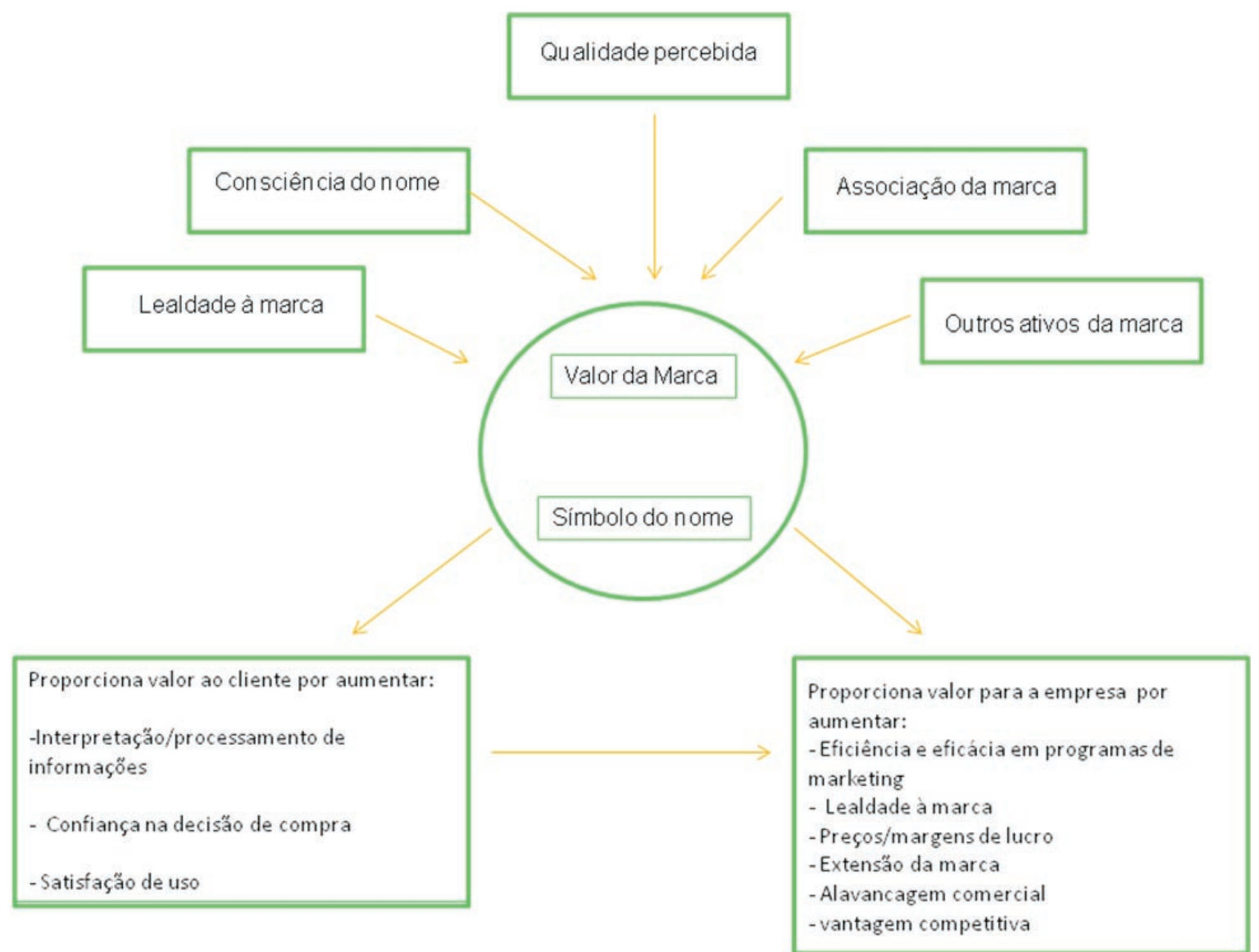

Figura 2 - Modelo de brand equity

Fonte: Aaker (1998, p.18).

Na mesma linha de pensamento, Feldwick (1996, p. 95) apresenta a seguinte classificaçao do termo valor da marca:

- valor total da marca como um ativo separado - quando é vendido ou atribuído, incluindo um balanço patrimonial (brand valuation);

- descrição das associações e crenças de avaliações que o consumidor tem sobre a marca; 
- a medidda da força de ligação do consumidor à marca, ou attachment dos consumidores - o que inclui conceitos como notoriedade, estima, qualidade percebida e lealdade (brand strength).

\section{Desenvolvimento da estratégia da marca}

As empresas têm como objetivo primário atender, mediante a oferta de produtos ou serviços, as necessidades e anseios de seus clientes e públicos. Dessa forma as organizações buscam oferecer, de maneira constante e repetitiva, a combinação ideal de atributos tangíveis e intangíveis, funcionais e hedonistas, visíveis e invisíveis em condições economicamente viáveis para ela. O poder de influência na mente dos consumidores é um fator importante na marca como conceito intangível.

Para Aaker (1991, p. 14), a marca não é somente um ativo estratégico, mas também uma fonte de vantagem competitiva para uma empresa com visão centrada no negócio. Em uma concepção complementar focalizada no consumidor, a marca poderá também ser entendida como a expressão de um conjunto com três tipos de benefícios proporcionados ao consumidor (AMBLER; STYLES, 1997, p. 23): (i) funcionais: relacionados com a qualidade intrínseca do produto/serviço e com a sua funcionalidade; (ii) econômicos: integradores de vantagens relativas avaliadas em termos de custo e de tempo; e (iii) psicológicos: de índole subjetiva, ligados às expectativas e percepções do consumidor determinantes para a sua satisfação.

A literatura potencializa o número significativo de autores que apenas consideram o brand equity como um ativo intangível adicional do produto, enquanto outros equacionam como valor financeiro da marca.

\section{O valor da marca para o mercado}

Como um ativo intangível, o valor da marca é representado por seu nome e sinaliza, para o consumidor, a origem do serviço/produto adquirido. Em muitos mercados, o que realmente importa é o nome da marca, ele representa seu negócio e sua base de vantagem competitiva vislumbrando ganhos futuros. O brand equity entra como uma estratégia para as empresas que pretendem investir nesse ativo e possibilita o gerenciamento adequado e coordenação coerente com a devida manutenção para criar e manter uma estrutura de marca consolidada e valorizada no mercado. O desafio da construção da marca é compreender os elos entre os ativos da marca e o desempenho futuro, de forma que as atividades de construção da marca possam ser justificadas e trabalhadas adequadamente ao longo prazo.

A valorização da marca possibilita programas para atrair novos consumidores e reconquistar os antigos, lealdade à marca através da qualidade e satisfação percebida, economia com promoções (premium price), impulso no canal de distribuição e vantagem competitiva.

\section{Categorias do brand equity}

O brand equity possui cinco categorias de ativos e passivos ligados a uma marca e cria valor não somente ao consumidor como também para a empresa. A figura 3 busca explicar o conceito de brand equity de forma estrutural e dinâmica (AAKER,1998). 


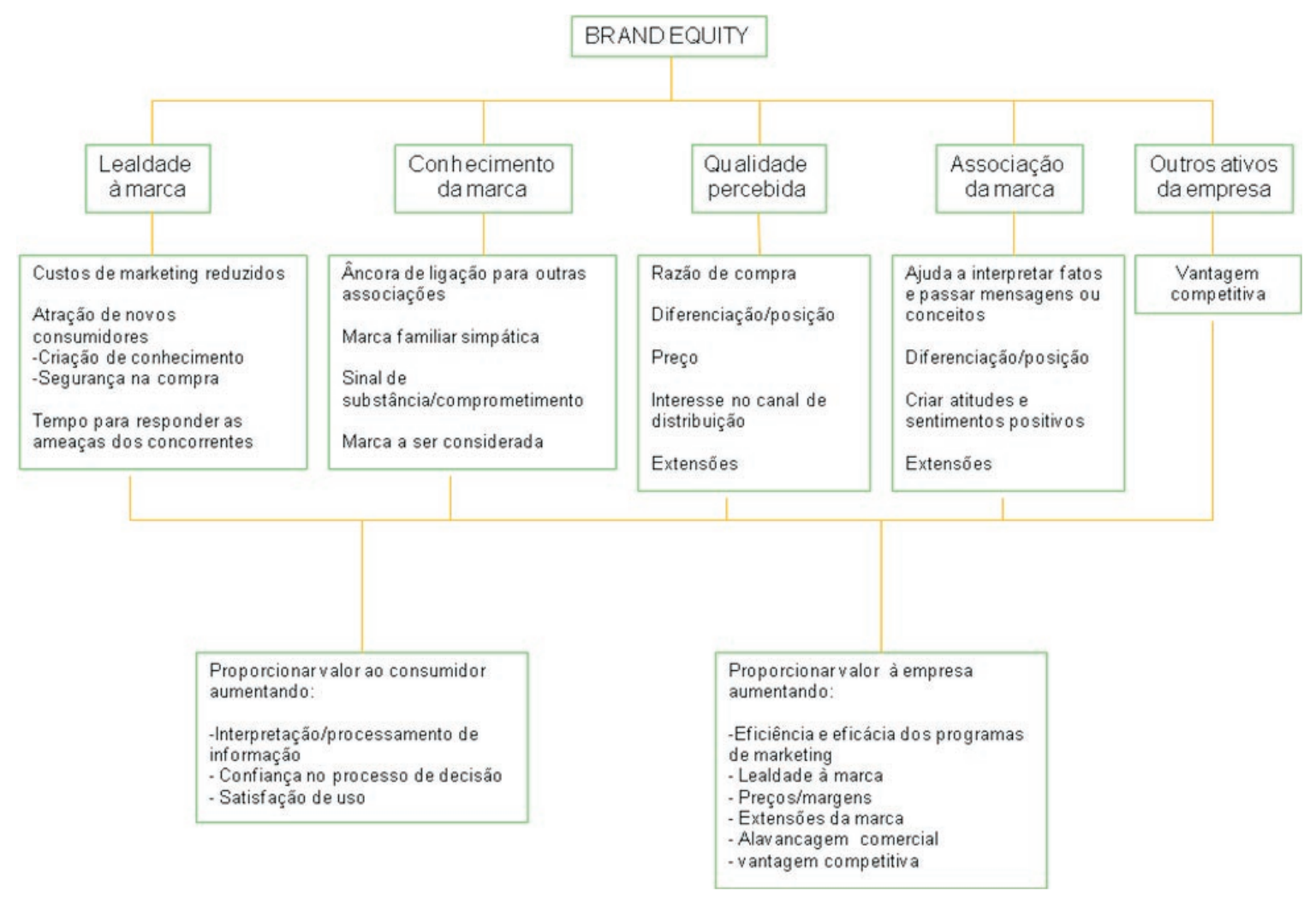

Figura 3 - Categorias do brand equity Fonte: Aaker (1998).

( As cinco categorias (Lealdade à marca; Conhecimento da marca; Qualidade percebida; Associação da marca e Outros ativos da empresa), descritas na figura 3, revelam os ativos que devem ser investidos para construção do branding:

- lealdade à marca: a lealdade dos consumidores reduz a vulnerabilidade da ação competitiva. Uma alta lealdade implica melhores negócios com o mercado, uma vez que os consumidores já possuem expectativas contempladas pela marca;

- conhecimento da marca: as pessoas tentem a comprar uma marca conhecida por se sentirem confortáveis e confiáveis com o que já lhe é familiar. O fato de a marca ser conhecida já a torna uma alternativa forte de compra;

- qualidade percebida: é uma característica mensurável da marca, influencia diretamente no poder de compra e lealdade à marca. Pode-se também gerar o premium price ou ser a base para extensão da marca;

- associação da marca: a associação forte possibilita a extensão de uma marca, um estilo de vida, credibilidade, segurança e personalidade que podem mudar a experiência de uso do mercado. Exemplo: a associação com o Ronald McDonald pode criar uma atitude ou um sentimento positivo ligado a uma marca como McDonald's;

- outros ativos da empresa: os ativos, para serem considerados relevantes, devem estar relacionados à marca, como patentes, marcas registradas, relacionamento com canais de distribuição, entre outros. Esses ativos são valiosos se puderem impedir ou inibir as ações dos concorrentes de erodir a base e lealdade dos consumidores. 


\section{CASO VALE}

\section{Perfil da empresa}

A Vale é uma mineradora pioneira que produz e comercializa minério de ferro, pelotas, níquel, concentrado de cobre, carvão, bauxita, alumina, alumínio, potássio, caulim, manganês e ferroligas. Com foco no crescimento e diversificação de suas atividades em mineração, a empresa investe em pesquisa mineral e tecnologias voltadas para a melhoria contínua de suas atividades nos cinco continentes. Em novembro de 2007, a Vale do Rio Doce passou a ter um só nome: Vale. A nova marca surgiu para expressar a personalidade da organização em âmbito global. Foram realizados estudos de mercado mundial, pesquisas com os empregados e, com base nesses dados, identificado os atributos que melhor representam a Vale e tudo o que a diferencia das demais empresas.

A indústria da mineração tem mudado com a globalização, a sua consolidação cria poucos clientes com forte poder de compra. Nesse contexto, empresas de mineração com marcas fortes terão a oportunidade de se diferenciarem, dirigirem a preferência do mercado, e cobrar mais por seus produtos e serviços. A consolidação da indústria de mineração pressiona as poucas empresas do setor que estão lutando pelos mesmos clientes, recursos e capital humano. Devido a essa realidade a Vale investe na expansão e valorização de sua marca, como estratégia de marketing e mercado, a Vale mudou seu nome impulsionando ativos que agregam valor e posicionamento no mercado mundial.

\section{Projeto valor da marca}

Para estudar e executar a mudança de marca, a Vale criou o projeto de Gestão da Marca, envolvendo inúmeras áreas da organização. Com início no ano de 2004, a meta do projeto é implantar $100 \%$ da nova marca até o ano de 2010. A partir desse projeto, a empresa redefiniu sua missão, visão e valores, para orientar as ações no relacionamento com os stakeholders e na gestão dos impactos de suas atividades no âmbito social.

Para a Vale, a marca possui função econômica, como: obter licença social para operar; entrada no mercado mundial; atuar em novos setores como franquias; alinhar objetivos e metas nas várias unidades de negócios; recrutar e reter talentos humanos de qualidade; ampliar o marketing share, ser o fornecedor preferido no mercado e comunicar maior desempenho, contribuindo na valorização do mercado de capital aberto. O projeto de branding da Vale traz, como principal desafio, o desligamento da marca antiga pelo share of mind e o posicionamento da identidade da empresa principalmente para o público interno.

\section{Estratégias da Vale para agregar valor ao seu branding}

Existem duas abordagens básicas que orientam os estudos relacionados ao branding equity: a determinação do valor patrimonial da marca e a busca pelo melhor aproveitamento (produtividade) dos recursos do composto de marketing. Ambas, na verdade, complementamse, mas, enquanto a primeira busca a correta determinação do valor contábil da marca para fins de apropriação em balanço e também com o objetivo de facilitar negociações entre empresas em questões relativas a fusões e aquisições, a segunda abordagem centra o seu foco na real efetividade do marketing que é praticado pelas empresas, como a Vale, considerando a marca como o elemento unificador de todas as suas ações mercadológicas.

Para Kottler e Armstrong (1998, p. 195), a definição de marca é:

[...] marca é um nome, termo, signo, símbolo ou design, ou uma combinação desses elementos para identificar os produtos ou serviços de um vendedor ou grupo de vendedores e diferenciá-los dos seus concorrentes. A marca é uma promessa do vendedor de oferecer, de forma consistente, um grupo específico de características, benefícios aos seus compradores. 
Diante do atual cenário de mercado de mineração e o posicionamento da Vale, a empresa percebeu a necessidade de utilizar sua marca como um fator determinante no momento de escolha de compra e atuação intangível na chamada brand strength, que é a força que a marca possui junto ao seu público stakeholders em geral.

O projeto de branding da Vale tem o objetivo de gerar visibilidade, percepção e transformação para consolidar a marca Vale no mercado mundial. Foi estruturado para atuar com ações de comunicação e capacitação, a fim de incentivar a cultura da marca na empresa e atuar no relacionamento com seus stakeholders.

A Vale busca, em seu projeto, identificar os ativos e prática-chave sobre os quais possa basear sua vantagem competitiva para desenvolvê-la e mantê-la com eficácia. Para o sucesso do projeto, a empresa integrou as áreas-chave como fator crítico de atitudes positivas, provocando extensões em suas ações estratégicas. As áreas envolvidas são: Áreas de Negócios; Serviços Compartilhados; Saúde e Segurança; Desenvolvimento e Recursos Humanos; Planejamento Estratégico; Tecnologia da Informação (TI) e Segurança Empresarial. O propósito de integrar áreas diversificadas foi para facilitar e apoiar a implantação da nova marca na empresa, reduzindo a resistência à mudança encontrada no âmbito interno.

As estratégias de branding da Vale não estão presas a ações de curto prazo, que não fazem parte do objetivo do branding. O desafio do branding da Vale é absorver a integração dos ativos da marca e desenvolver estratégias que possam ser trabalhadas em longo prazo, a fim de melhorar o desempenho da marca Vale no mercado. A gestão da marca busca alinhar a realidade mercadológica com os valores e cultura que a mineradora possui.

\section{A nova marca}

A nova marca simboliza a busca incessante pela excelência e, sobretudo, a crença no desenvolvimento sustentável, a partir da relação harmônica entre o homem, suas organizações e a natureza (Figura 4). As associações, tanto de formas quanto de cores, fazem referência ao nome da empresa, à diversidade da natureza, atividade da indústria e sua origem brasileira. As cores e as formas ainda projetam a disciplina da empresa focada a se tornar a maior e melhor empresa mineradora do mundo, o que está sendo construído de modo integrado com as comunidades onde a empresa atua e toda a sociedade, com ética e respeito à diversidade.

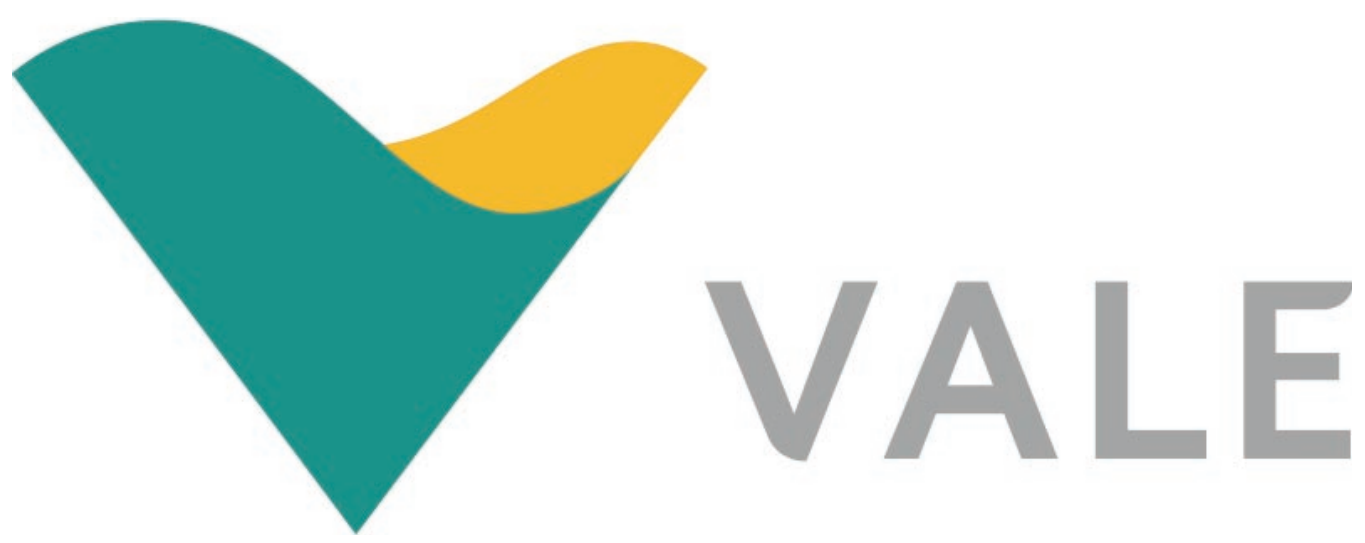

Figura 4 - Nova marca e nome da Vale 


\section{Ativos do branding da nova marca}

O projeto Gestão da Marca trabalha as estratégias de branding que remetem à consciência do nome, lealdade à marca, qualidade percebida, associação da marca e outros ativos estudados por Aaker (1998), tais como:

a) Associação à marca: a nova marca da Vale ajuda a interpretar os fatos e passa mensagem e conceitos do que é a organização. Sua criação intencional foi para despertar atitudes e sentimentos positivos nas pessoas e comunidades em que a empresa atua diretamente, reforçar a motivação em seus funcionários e facilitar a extensão de seus negócios, principalmente no exterior. A forma da Marca remete à letra "V" de Vale (valley), vitória (victory) e valor (value). O design possui significado global - um coração. O coração da Vale, empresa mundial de origem brasileira, representa a paixão com que seus empregados trabalham. A cor verde representa a natureza e os Vales, o amarelo representa a riqueza mineral que são transformados em "ingredientes essenciais para nossa vida diária" (slogan da campanha da mudança de marca e posicionamento da empresa). Como percepção subliminar, a logomarca também possui o símbolo infinito 90 que demonstra a melhoria contínua preservada e planejada pela empresa;

b) outros ativos da empresa: de acordo com a análise de mercado Lippincott-Cauduro (2007), utilizada pela Vale, as características da situação atual das indústrias de mineração são:

- volatilidade e queda dos preços de commodity;

- aumento do rigor nos regulamentos e limitações ambientais;

- consolidação na indústria da mineração e demais setores;

- aumento dos custos de operações;

- aumento no risco geopolítico nos territórios ricos em minerais;

- necessidade de diversificação de produtos e consolidação maior na indústria;

- aumento da pressão pública em relação à sustentabilidade através da responsabilidade sócio-ambiental;

- demanda por avanços tecnológicos para maximizar as extrações minerais.

A estratégia adotada pela Vale é focada na vantagem competitiva. As empresas de mineração não possuem uma arquitetura clara e forte de suas marcas; com essa percepção, a Vale parte na frente com a estratégia de valorização da marca.

Ao implantar o projeto de brand equity e utilizar seus facilitadores, a Vale tem a oportunidade de se tornar relevante ao público, trazer a indústria da mineração à tona e redefinir sua percepção no mercado, contribuindo para o desempenho financeiro positivo da mesma;

c) Lealdade à marca: a Vale aumenta a atração de novos consumidores, proporciona conhecimento aos seus públicos, fortalece a segurança da compra e seu relacionamento com a comunidade. Ao renovar sua identidade a empresa busca apoio para posicionamento de sua nova marca, demonstrando seus compromissos com a sociedade; expande sua participação emocional nas pessoas, atuando como um facilitador para obter a licença social para operar e fortalecer o elo com seus clientes. Segundo o Bloomberg e Sisbacen - Banco do Brasil, o valor de mercado da Vale é equivalente a U\$ 182.542 bilhões. O posicionamento da marca Vale evidencia as características positivas da empresa. Um posicionamento eficaz indica aos públicos com os quais a empresa se relaciona como define seu negócio, os benefícios que ela oferece e o que a marca tem de especial;

d) Conhecimento da marca: a escolha do novo nome deve-se às vantagens e desvantagens estudadas pela pesquisa de mercado da empresa. Como vantagens, destacam-se: nome familiar e preferido no Brasil; possui conotações positivas com a palavra, incluindo grandes visões externas: Vale, várzea, valor; simpático e de som aberto; fácil de lembrar e de soletrar; captura valores do 
nome onde já é conhecido; "Vale.com" - website ativo e disponível para venda. Como desvantagens, destacam-se: requer investimento para comunicar a mudança fora do Brasil; perda no nome da marca antiga CVRD (Companhia Vale do Rio Doce) e pode soar informal e muito casual para a indústria de minério.

Ao optar pelo nome Vale a empresa busca desvincular da imagem de estatal no Brasil e vincular-se aos atributos de posicionamento da marca, tais como: integração com a comunidade; imagem confiável; respeito à diversidade cultural; valor aos acionistas. Nessa direção, a empresa elaborou uma estrutura que nomeou com "Estrutura da estratégia da Marca" (Figura 5).

\section{Estrutura da estratégia da Marca}
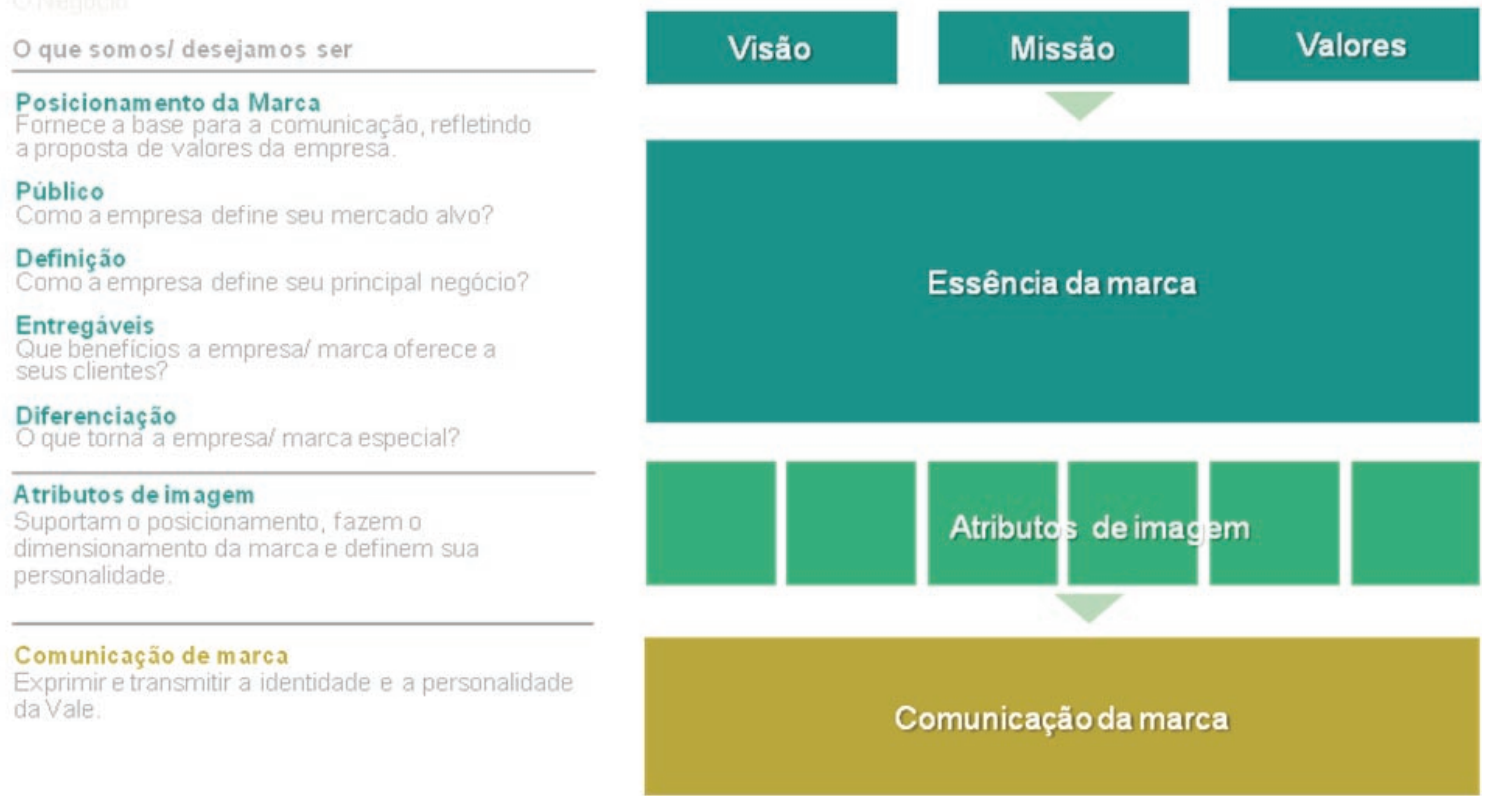

Figura 5 - Estrutura da estratégia da marca

Fonte: material institucional do projeto de Mudança da Marca.

O antigo nome ou razão social - Companhia Vale do Rio Doce - era institucional e emitia frieza em seu relacionamento com o público (Figura 6). Retratava burocracia, uma sigla antiga e pesada ligada à posição de estatal, e não transmitia conceitos de emoção e sentimentos relacionados às comunidades e stakeholders.
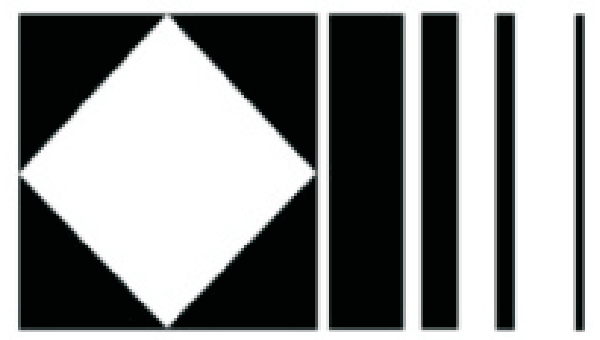

\section{Companhia Vale do Rio Doce}

Figura 6 - Nome e marca antiga da Vale 
e) Qualidade percebida: a marca Vale é a assinatura de comunicação da empresa e suas subsidiárias. Não deve ser confundida com a razão social ou nenhuma outra forma de dominação legal. O que quer dizer que a empresa somente quer vincular sua marca à qualidade percebida e não relacionar à razão social, que remete à degradação das riquezas naturais do país. Ao aguçar o interesse em seu canal de distribuição e extensão, a empresa desvincula, estrategicamente, do antigo para expandir com o novo no mercado globalizado. Com o branding, a Vale se aproxima com palavras mais suaves, como o slogan "ingredientes essenciais para vida diária", e diferencia sua posição no mercado.

A qualidade percebida é tendenciosa ao emocional humano e ao lado social das comunidades e políticas. Dessa forma, a empresa pretende aumentar seu valor competitivo no mercado e reforçar as outras marcas da organização.

\footnotetext{
A nova marca representa o que nós já fizemos e dá muita emoção, um sentimento muito bom. Primeiro a Vale recebeu esse nome do pessoal dentro da casa, que já dizia - Vale e só depois foi para a mídia.

Saímos do regionalismo e saímos pro mundo. (Diagnóstico Uniformes - Nova Marca Pesquisa Rebouças Associados, jan. 2008).
}

\section{Medição do valor da marca}

Ao levar em consideração que o Brasil é um país onde as marcas são valorizadas pelo processo emocional relacionado aos produtos e empresas, a Vale intensifica suas estratégias de branding focadas no lado humano e cultural. De acordo com o depoimento de Gilson Nunes ao jornal Gazeta Mercantil (7 de setembro de 2008), existem estudos que comprovam que $66 \%$ do valor das empresas são originados de ativos intangíveis, e a marca representa, em média, 65\% desses ativos. Uma das formas de se medir a marca é estabelecer o valor de mercado das empresas listadas na bolsa, taxa estimada e histórica do crescimento de vendas, estrutura de capital próprio e terceiro, e a taxa de desconto refletindo o risco da marca. Ao trabalhar com a emoção do consumidor a Vale causa um efeito de proteção da marca, em que os públicos passam a defendê-la e a criar relações de afeto e protecionismo.

De acordo com o gerente geral da comunicação e imagem da Vale, Paulo Henrique Soares (2008), em uma entrevista concedida à Múltipla Comunica (2008), os conceitos mais importantes no momento de traçar o planejamento da mudança da marca foram as premissas que devem ser a base de toda área de comunicação corporativa: alinhamento, planejamento das atividades, alinhamento de discursos para todos os públicos, ou seja, um discurso para a imprensa, um discurso para o empregado e, principalmente, a integração entre as várias áreas de comunicação. Segundo Soares, $10 \%$ do orçamento de comunicação é destinado às atividades internas da Vale; dessa forma, a empresa prioriza os empregados e seu público interno como um todo.

Para avaliar a ativação de seu projeto de branding, a Vale utiliza-se de alguns modelos de medição apresentados no mercado. Auditorias internas e externas são realizadas constantemente, os resultados são avaliados pela área de comunicação e as ações necessárias são planejadas para atuar. Recentemente a empresa iniciou um trabalho de capacitação de seus gestores para potencializá-los na comunicação face a face e fortalecer o projeto de Mudança de Marca. Nesse processo, é fundamental que a alta gestão da empresa esteja envolvida e comprometida com as decisões e resultados alcançados. 
Como avaliação do projeto, os participantes encontram-se, quinzenalmente, na unidade do Rio de Janeiro, para reuniões internas e integração da equipe de branding. Cada unidade possui um representante do projeto e estão dedicados $100 \%$ às ações de branding, valorização e posicionamento da nova marca. Como medição do status das atividades propostas, os gerenciadores controlam e administram o projeto por meio de vídeo conferência e envio de materiais por e-mail, como exemplificado na figura 7.

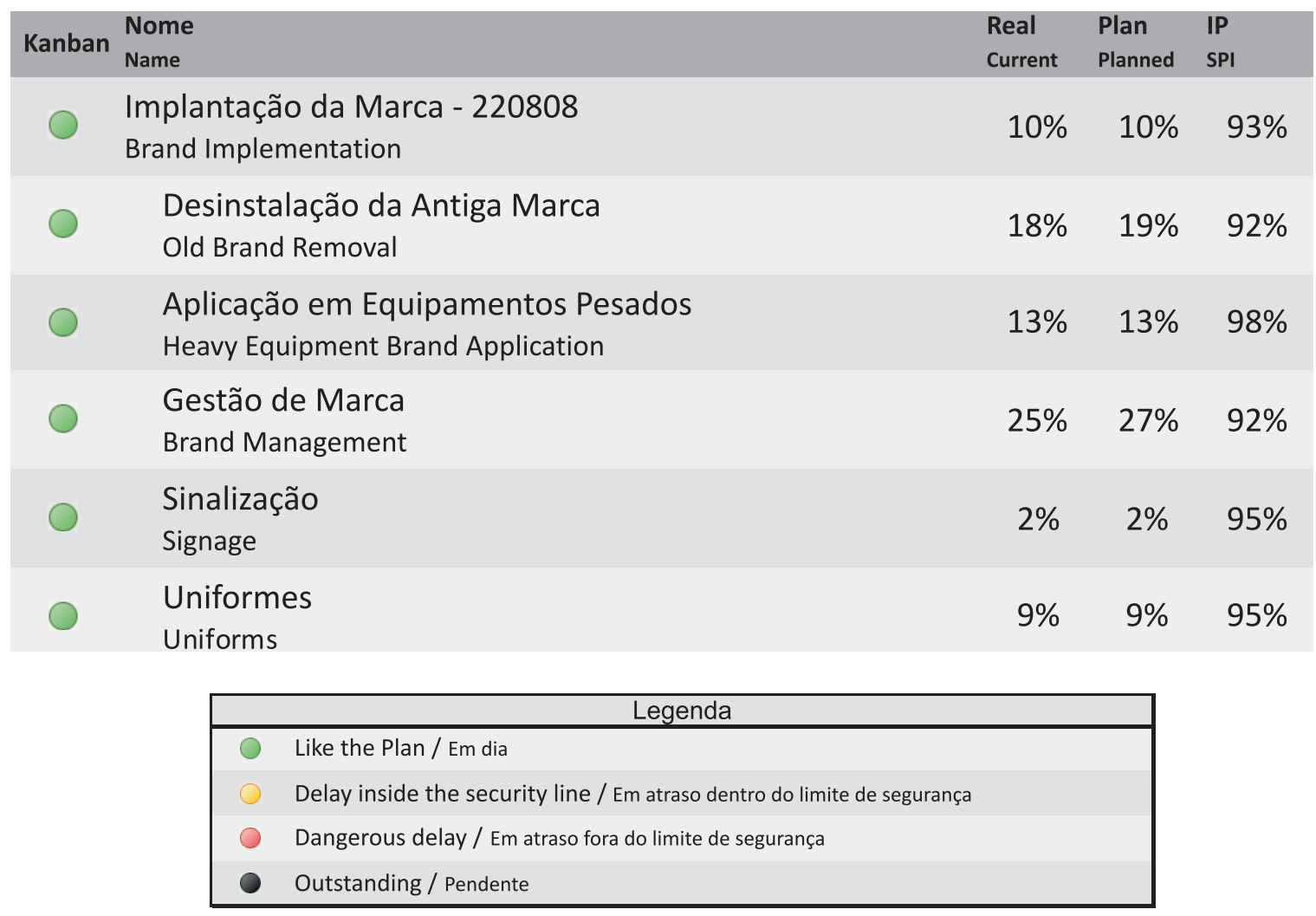

Figura 7 - Painel sinótico divulgado para a equipe do projeto

Segundo Ries (1996), para ter sucesso com a sua marca, a empresa deve construir uma palavra ou conceito na mente de seu público e, para fortalecê-la, é indispensável posicionar a marca em um espaço ainda não focalizado, ou seja, a expansão da marca. Para Porter (1986), a estratégia de posicionamento deve ser: descobrir um novo mercado e investir em suas forças para estabelecer o posicionamento a partir de um estudo de comportamento da concorrência, pressão dos fornecedores, expectativas dos clientes, oportunidades e ameaças do setor.

[...] o conhecimento das capacidades da empresa e das causas das forças competitivas realçará as áreas em que deve enfrentar ou evitar a competição. (PORTER, 1986, p.41).

Com ações de comunicação e marketing, a Vale busca fortalecer sua marca na mente dos compradores e conotar atributos positivos em benefícios e valores à empresa. A construção da nova marca da Vale exige gerenciamento de todo o contato com a marca que o cliente, empregados, fornecedores e distribuidores possam ter. A qualidade do relacionamento com a empresa por parte de seus públicos é, minuciosamente, tratada no projeto de mudança da marca. Algumas ações retratam essa postura: todos os veículos internos e externos da empresa 
tiveram sua logomarca alterada, os valores da empresa foram trabalhados durante semanas para interagir com os empregados, jornal mural, identidade visual das unidades, cartão de visitas, crachás e uniformes foram planejados para serem substituídos ao longo do projeto. A comunicação realizou entrevistas com os empregados de todas as unidades com a pergunta "o que este valor significa para você na empresa e na vida?". Peças de comunicação foram distribuídas aos empregados para aproximar a nova marca do público interno.

As empresas parceiras e contratadas da Vale também participaram de reuniões para apresentação da marca e sua correta forma de utilização. Outra estratégia adotada pela área de comunicação foi o relacionamento com a comunidade, em Ourilândia do Norte (PA), os representantes da Vale reuniram-se com a sociedade, inclusive tribos indígenas. Para cada público a empresa utilizou uma abordagem de apresentação de sua nova marca e os benefícios que a nova posição da Vale trará para a comunidade.

A Vale aplica estratégias de valorização da marca desde 2004; em 2007, seu reposicionamento no mercado foi estudado e avaliado com a construção da nova marca - Vale - para fins de gerar visibilidade, percepção e transformação, consolidando a marca no mercado mundial. Muito se discute sobre o valor intangível da empresa, e a gestão da marca potencializa isso, a Vale acredita na expansão e valorização de sua identidade visual estrategicamente, para manter e impulsionar sua posição no mercado global. A repercussão da nova marca Vale foi considerado o melhor caso de Rebranding de Líder Coorporativo de 2007 pela empresa Identity Works, dirigida por Toony Spaethy.

\section{Conclusão}

O poder da marca é utilizado de forma estratégica para alavancar vendas e competitividade no mercado. Para a Vale, sua marca anterior era voltada para o âmbito interno, sem muito significado com seus valores e postura mercadológica. A empresa busca, com o Projeto de Gestão da Marca, uma nova postura cultural e expressão de seu valor para o mundo.

A empresa planejou seu projeto de mudança de marca através de estudos e pesquisas de mercado para gerar um novo símbolo que possui as características relevantes de sucesso brasileiro. Seu projeto iniciou de forma gradativa, perante o diagnóstico apresentado e seu universo de atuação geográfica. Para a Vale, a mudança cultural é estratégica e irreversível, pois a construção de sua nova marca e aplicação do branding é uma tarefa de todos os empregados, englobando as comunidades locais.

Com o reposicionamento da marca, a empresa possui como desafio a desvinculação da antiga marca no mercado, a correta utilização de suas estratégias de valor da marca e expansão da mesma, o envolvimento dos empregados no processo de mudança e a criação de uma nova cultura interna.

Com o brand equity, a Vale busca posicionar-se na mente e percepção de seu público, consolidar argumentos de proteção e valorização da empresa como essencial à vida das pessoas. Outro benefício observado com o posicionamento da Vale foi o aumento do valor de sua marca no mercado financeiro, através de um arquitetura sólida e consistente, a empresa conquista share of mind de empresas que possuem ações na bolsa (VALOR ECONÔMICO, 2008), esse resultado mostrou a relevância de se investir no fortalecimento da marca para tentar reduzir a diferença entre seu valor real e valor de mercado. 
Pode-se perceber que o foco inicial da empresa é seu público interno, o projeto de mudança da marca possui ações específicas voltadas para seus empregados e comunidades locais. Já para o demais públicos, a empresa utiliza a estratégia de nova postura e posicionamento mundial, relacionando sua atividade primária à necessidade das pessoas. O brandy equity sensibilizou as pessoas e aproximou-as dos valores propostos pela Vale.

\section{Referências}

AAKER, D. Managing Brand equity. New York: Free Press, 1991.

AAKER, David. Marcas Brand Equity: gerenciando o valor da marca. São Paulo: Negócio, 1998.

AMBLER, T.; STYLES, C. Marketing in the morden world: networks of silk. London: Prentice Hall, 1997.

BIEL, A. Brand equity and advertising. Hisdale, NJ: Laurence Eribaum Associates, 1993.

FELDWICK, P. Do we really need brand equity? In: CALLER, Linda (Ed.). Researching brands. Netheriands: Esomar, 1996. p. 93-117.

LOURO, S. Maria João, RAE. Revista de Administração de Empresas, São Paulo, v. 40, n.

2, p. 26-37, abr./jun. 2000.

KOTLER, Philip; ARMSTRONG, Gary. Princípios de marketing. 7. ed. Rio de Janeiro: LTC: 1998.
MÚLTIPLA COMUNICA. Disponível em: <http:// multiplacomunica.com.br/site/home/ default.asp?titulo = entrevale $\&$ staticpage $=$ yes. Acesso em: 05 dez.2008.

RIES, Al. Foco: uma questão de vida ou morte para sua empresa. Trad. Maria Cláudia Santos R. Ratto. São Paulo: Makron Books, 1996.

PORTER, Michael E. Estratégia competitiva: técnicas para análise de indústrias e da concorrência. Rio de Janeiro: Campus, 1986.

VALOR ECONÔMICO, Marcas que seduzem. Caderno: eu \& investimentos. 19 ago. 2008.

GAZETA MERCANTIL. Suplemento Especial. 5, 6 e 7 set. 2008.

VALE. Disponível em: <http://www.Vale.com>. Acesso em: 26 nov. 2008. 